\title{
Sample Management Across the National Ecological Observatory Network
}

\author{
Christine M Laney ${ }^{\ddagger}$, Katherine E LeVan ${ }^{\ddagger}$, Claire K Lunch ${ }^{\ddagger}$, Katherine M Thibault ${ }^{\ddagger}$ \\ ‡ Battelle, National Ecological Observatory Network, Boulder, CO, United States of America
}

Corresponding author: Christine M Laney (claney@battelleecology.org)

Received: 29 Mar 2018| Published: 18 May 2018

Citation: Laney C, LeVan K, Lunch C, Thibault K (2018) Sample Management Across the National Ecological Observatory Network. Biodiversity Information Science and Standards 2: e25351. https://doi.org/10.3897/biss.2.25351

\begin{abstract}
From 81 study sites across the United States, the US National Ecological Observatory Network (NEON), generates $>75,000$ samples per year. Samples range from soil and dust deposition material, tissue samples (e.g., small mammals and fish), DNA extracts, and whole organisms (e.g., ground beetles and ticks). Samples are collected, processed, and documented according to protocols that are standardized across study sites and according to the needs of the ecological research community for future studies. NEON has faced numerous challenges with managing data related to these many diverse physical samples, particularly when data are gathered at numerous steps throughout processing. Here, we share these challenges as well as solutions, including innovative semantically driven software tools and processing pipelines that manage data from each sample's point of collection to its ultimate fate (consumption, archive facility, or partnering data repository) while maintaining links across sample hierarchies.
\end{abstract}

\section{Keywords}

semantics, samples, specimens, data management, collections, controlled vocabularies 
2

Laney $\mathrm{C}$ et al

Presenting author

Christine M Laney 